\title{
Healing Following Simple Gingivectomy. A Tritiated Thymidine Radioautograpbic Study. I. Epithelialization
}

\author{
BY W. O. ENGLER, * D.D.S., M.S., S. P. RAMFJORD, ${ }^{* *}$ L.D.S., PH.D., AND \\ J. J. HINIKER,*** D.D.S.
}

\begin{abstract}
PREVIOUS STUDIES in experimental animals ${ }^{1-4}$ and humans ${ }^{5-8}$ have established a generally accepted pattern of healing following simple gingivectomy. However, much is yet unknown concerning the tissue migration and synthesis which lead to restoration of form and function following surgical removal of gingival tissues. Knowledge on details regarding timing, duration and order of cell proliferation also is incomplete. The purpose of the present investigation was to make a sequential study of cell proliferation and dynamics of healing following simple gingivectomy through a combination of histologic and radioautographic techniques.
\end{abstract}

Administration of tritiated thymidine to experimental animals provides a radioautographic method for demonstration of cellular synthesis of DNA in preparation for mitosis. Thymidine is incorporated into cells during their premitotic S-Phase ${ }^{9}, 10$ and when tagged with tritium, demonstrates in radioautographs the cells that were synthesizing DNA at the time of intravenous administration of the isotope. This technique combined with conventional histologic methods provides an opportunity to study mitotic activity and migration of cells with greater accuracy than reported in the previous studies of healing following gingivectomy. This paper will be concerned mainly with regeneration of the epithelium, while the findings related to the connective tissues will be reported in a subsequent paper.

\footnotetext{
*U.S. Department of Health, Education, and Welfare, Public Health Service, National Institutes of Health, National Institute of Dental Research, Dental Director, Oral Medicine and Surgery Branch, Bethesda, Maryland.

**School of Dentistry, The University of Michigan, Ann Arbor, Michigan.

***Veterans Administration, Washington, D.C.
}

\section{MATERIALS AND METHODS}

Clinical Procedures. Three healthy adult male rhesus monkeys (Macaca Mulatta), at least 5 years old, ${ }^{11}$ and weighing 11.8 , 9.1 , and $7.3 \mathrm{kgs}$. respectively, were selected. Adult males were used to avoid fluctuation in epidermal mitotic rate reported to occur in females related to the estrus cycle. ${ }^{12}$

The animals had varying amounts of supra and subgingival calculus and moderately severe marginal gingivitis with crevice depths of 2 to $4 \mathrm{~mm}$. All teeth were scaled 2 weeks prior to the experimental procedures in order to remove most of the calculus and thereby establish as standardized presurgical conditions as possible.

Simple gingivectomies were performed around $21 / 2$ posterior teeth at predetermined time intervals. The marginal gingiva was excised to the bottom of the epithelial attachment, as located by a periodontal probe (U. of Mich. \#0), and with a regular beveled incision. The resultant wounds were about $3 \mathrm{~mm}$ wide on both the buccal and lingual sides of the teeth. Following the gingivectomy, the teeth were rescaled for removal of residual calculus and the exposed tooth surfaces were planed with curettes. No surgical dressing was used. Control areas were left untreated in all three monkeys.

The gingivectomies were performed at $35,21,14,9,7,5,3$ days and at $49,37,25$, $13,9,5$, and 2 hours prior to sacrifice of the animals. One hour prior to sacrifice, each animal was injected intravenously with 1 microcurie of tritiated thymidine,

\footnotetext{
*New England Nuclear Corporation, Boston, Massachusetts.
}

Page 36/298 


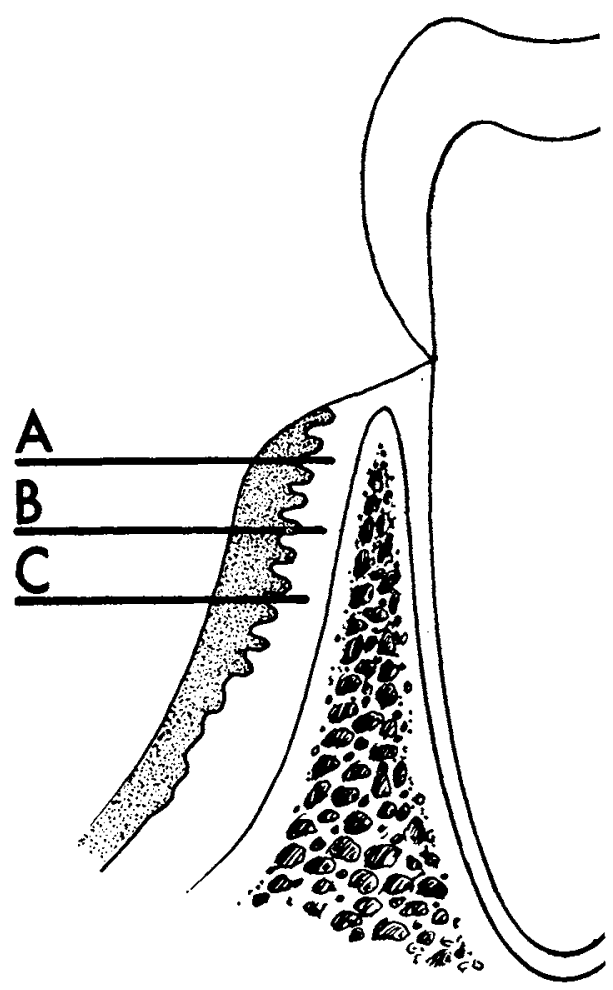

Fig. 1. Diagram of wound margin following gingivectomy demonstrating epithelial zones of attached gingiva used in counting.

(specific activity 6.7 curies per millimole) per gram of body weight. The administrations of tritiated thymidine were performed at 9 a.m. and the animals were sacrificed at 10 a.m. to avoid possible diurnal changes, although these supposedly do not affect wound healing. 13

Laboratory Procedures. A complete necropsy of the animals was done and sections were studied from internal organs to exclude the possibility of systemic diseases which might have influenced tissue metabolism and healing. No significant systemic disorders were found.

The jaws with the teeth and contiguous soft tissue were fixed in $10 \%$ neutral buffered formalin for 3 weeks, divided into segments bucco-lingually with a band saw and diamond disks, and decalcified in $20 \%$ EDTA adjusted to a $\mathrm{pH}$ of 7.4 with sodium hydroxide. The tissue blocks were em- bedded in paraffin and sectioned at 8 microns.

Radioautographs of jaw specimens were prepared by the dipping technique previously reported ${ }^{14}$ using $\mathrm{NTB}^{-3}$ emulsion.* After 4 weeks of exposure, the radioautographs were developed, fixed, the sections stained with Ehrlich's acid hematoxylin and mounted with Permount. Several sections from each block were stained with hematoxylin and eosin without adding film for histologic study.

Counting Procedures. Since initial alteration of labeling ${ }^{15}$ and changes in the number of mitoses 12,16 in epithelium occur within 1.5 to $2.0 \mathrm{~mm}$ from the edge of a surgical incision, counts were made of an area of attached gingival epithelium extending $1.71 \mathrm{~mm}$ from the wound margin. For convenience, this area was divided into 3 zones designated as zones $\mathrm{A}, \mathrm{B}$, and $\mathrm{C}$ as in Fig. 1, each $0.57 \mathrm{~mm}$ in length. Counts were also made of corresponding zones in untreated specimens.

Radioactive indices were determined by counting at $430 \mathrm{x}$ the number of labeled and unlabeled cells in each epithelial area according to the method of Messier and Leblond.17 The ratio of the number of labeled cells to the total cell population was expressed in percentage as the radioactivity index.

\section{FINDINGS}

Prescaled Control Areas. The original gingivitis subsided markedly following the presurgical scaling. At the time of sacrifice, the gingivae appeared fairly normal in color, form and density, and exhibited little or no bleeding upon routine probing of the unoperated control areas. Histologic sections revealed normal keratinized gingival surface epithelium, and a thin well adapted epithelial attachment or cuff ending at or slightly apical to the cemento-enamel junction. Some lymphocytes and plasma cells

\footnotetext{
*Eastman Kodak Company, Rochester, New York.
} 
were present adjacent to the sulcus epithelium.

Radioautographs demonstrated labeled cells in the basal and lower spinous layer of the gingival epithelium, and occasionally in the connective tissues of the lamina propria. The radioactive indices for control areas from the three monkeys were $0.90 \%$, $1.37 \%$ and $1.46 \%$, which provided an average control index of $1.32 \%$.

\section{EXPERIMENTAL FINDINGS}

Two hours following gingivectomy the histologic sections revealed that the surface of the incision was relatively free of debris and was covered by a thin fibrinoid exudate in which were incorporated polymorphonuclear leukocytes. An acute inflammatory reaction, characterized by dilated vessels and emigration of leukocytes, had already been established in the connective tissues of the wound margin. The connective tissues beneath the incision, for a depth of approximately $0.2 \mathrm{~mm}$, exhibited disrupted collagen bundles and few fibrocytes.

Radioautographs over these sections showed labeled cells in the basal layer of the attached gingival epithelium at the wound margin. This labeling had taken place 1 hour following the gingivectomy. In the monkey having a control radioactive index of $1.37 \%$ the 1 hour radioactive index of the epithelium at the wound margin was $1.92 \%$. Connective tissue labeling was also comparable to that observed in control sections.

Five hours following simple gingivectomy, a well defined clot apparently had sealed the incision. The acute inflammatory reaction observed at 1 hour had progressed and many polymorphonuclear leukocytes were present in the connective tissues underlying the incision.

In the epithelium immediately at the wound margin and extending approxi- mately $0.7 \mathrm{~mm}$ along the adjacent attached gingiva, many of the cells of the spinous layer were enlarged, pale staining, and exhibited indistinct intercellular bridges 5 hours following gingivectomy. Interspersed between these swollen, hazy cells were chromatin masses from cells ruptured as a result of the incision (Fig. 2). The basal cell layer of the epithelium at the wound margin was normal in appearance, and stained deeply in contrast to the pale staining spinous layer. The 4 hours radioactivity index had not changed significantly from the control index.

Nine hours following gingivectomy, a band of basophilic cells, 5 to 6 cells in thickness, was present in the basal portion of the epithelium at the wound margin, and several of the basophilic cells in this region were labeled (Fig. 2). By 13 hours, migration was definitely established as the basophilic cells extended from the spinous and basal cell layers of the epithelium beneath the clot and the necrobiotic layer, on top of the underlying normal connective tissue (Fig. 2).

Radioactivity indices showed a slight tendency to increase above the radioactivity index of control areas during the first 12 hours following gingivectomy, but the increase was not statistically significant (Fig. 3). When individual radioactivity indices of the areas outlined in Fig. 1 were compared at the various time periods following gingivectomy, no definite pattern of wave-like premitotic activity along the epithelium at the wound margin could be discerned (Fig. 2).

Twenty-five hours following gingivectomy, the cells of the epithelium at the wound margin exhibited layering and staining typical of stratified squamous epithelium (Fig. 4). Migration from the basal and deeper spinous layers had advanced approximately. $0.4 \mathrm{~mm}$ across the wound. The connective tissues, which in shorter term specimens had appeared altered at the wound surface, were now heavily infiltrated with polymorphonuclear leukocytes. 


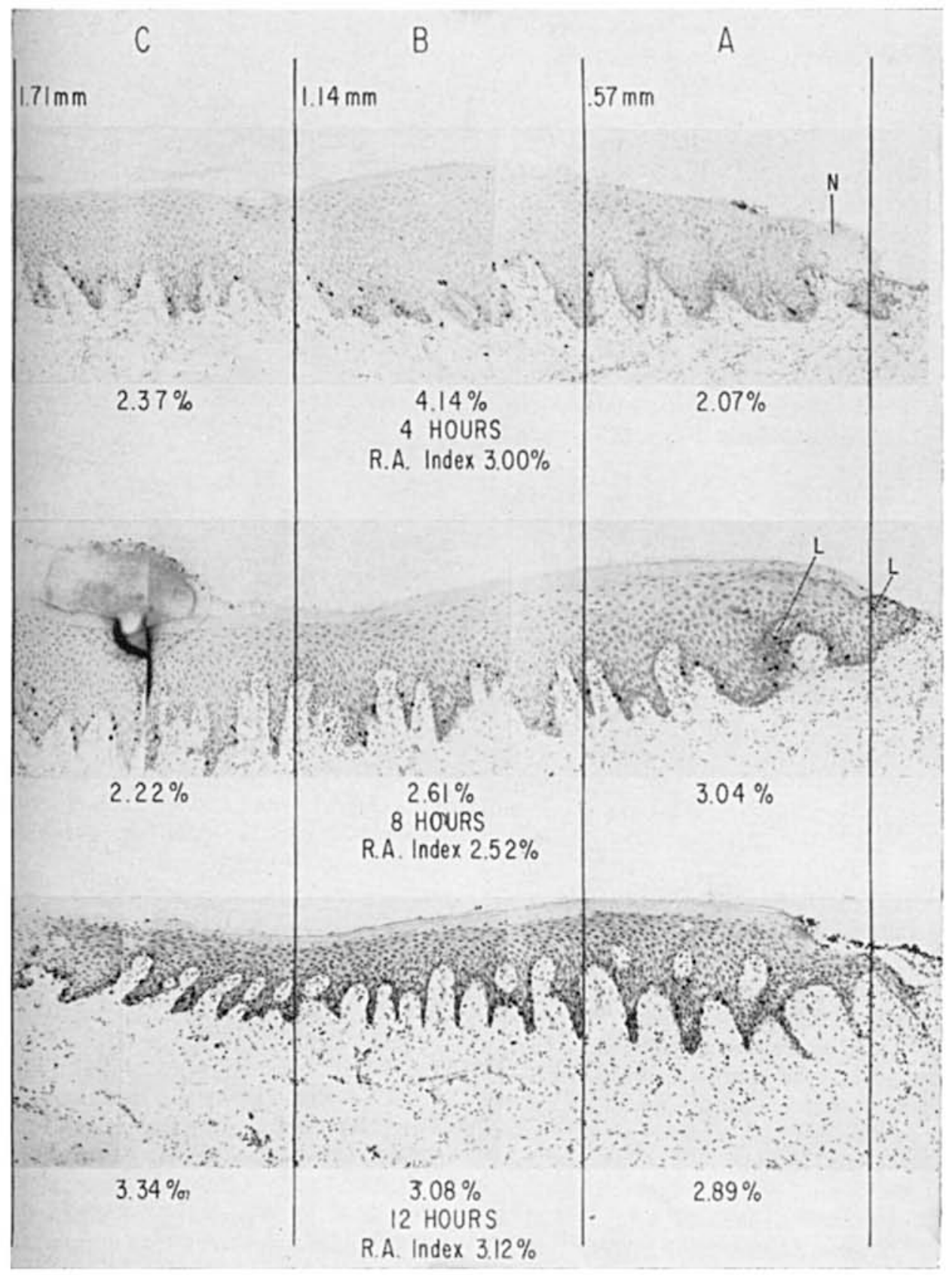

Fig. 2. Epithelium of attached gingiva at the wound margin divided into areas (A,B,C) for counting as depicted in Fig. 1. (Magnification x105). Top figure represents 4 hour radioautograph. (Five hours after gingivectomy). Necrosis in superficial layers of epithelium at wound margin ( $N$ ). Middale figure represents 8 hour labeling (L). Bottom figure represents 12 hour radioautograph. (Thirteen hours following gingivectomy). Migration of epithelial cells initiated at wound margin. 
Epithelial migration appeared to be occurring beneath this altered layer, with the epithelial cells moving as a sheet of loosely attached cells which wedged out into the connective tissue surface of the wound (Fig. 4).

Synthesis of DNA in the epithelium at the wound margin was greatly increased 24 hours following gingivectomy. The 24 hour radioactivity index was more than 12 times that of the control index and was the highest observed during the experimental period (Figs. 3, 4). This increase in DNA synthesis was limited to the basal and deeper spinous layers of the attached gingival epithelium within $2 \mathrm{~mm}$ of the wound margin (Fig. 4A). The number of labeled cells in the attached gingival epithelium at greater distances from the wound margin (Fig. 4A) was similar to the number observed in sections from control areas.

In several sections a few cells of the epithelial attachment had inadvertently been left during gingivectomy (Fig. 5). Many of these cells were labeled at 24 hours and had migrated towards the wound from the tooth surface. They appeared at the junction of the band of polymorphonuclear infiltrate and the underlying connective tissue.

Thirty-six hours following gingivectomy, a substantial decrease was noted in the synthesis of DNA by epithelial cells of the wound margin. Although the 36 hour radioactivity index was relatively high when compared to the control index of $1.32 \%$, it had decreased from the high index of $16.88 \%$ at 24 hours to $7.17 \%$ in the 12 hour period. From 36 hours to 5 days following gingivectomy, the radioactive index at the wound margin remained relatively constant with indices of $7.17 \%, 6.42 \%$, $6.77 \%$ and $5.91 \%$ being recorded at 36 hours, 48 hours, 72 hours, and 5 days following gingivectomy (Fig. 3)

Forty-eight hours following gingivectomy most synthesis of DNA was localized to epithelial cells immediately at the wound

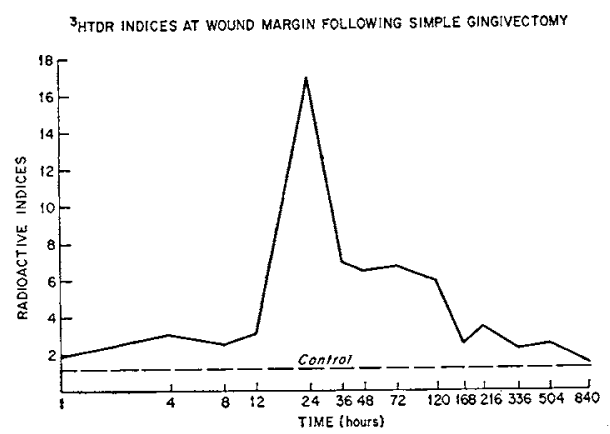

Fig. 3. 3HTDR indices at wound margin following simple gingivectomy. Note peak at 24 hours. Control level reached at 35 days.

margin. Several labeled cells also were present in the basal layer of the migrating epithelium (Fig. 6A). Near the advancing tip of the migrating epithelial wedge the connective tissue contained many polymorphonuclear leukocytes and fibroblasts loosely arranged in a honeycomb fibrin matrix. The connective tissue at the tip of the migrating epithelial wedge appeared to be more dense than the surrounding tissue but definite collagen bundles could not be seen (Fig. 6B). As the epithelial cells migrated, the connective tissue immediately beneath the new epithelium appeared to organize into distinct collagen bundles which abutted on to the basal layer of the migrated epithelium or the basement membrane.

From the 2 nd to the 5 th postoperative days the epithelium migrated slowly toward the tooth surface, reaching the vicinity of the tooth by the 5 th day (Fig. 7). At the original wound margin the epithelium was stratified and several rete pegs were present. The new epithelium covering the wound was several cell layers thick and was not keratinized. Labeled cells were present in the basal layer along the length of the new epithelium. The surface level of the newly epithelialized area closely approximated that of the initial incision.

Between the 5 th and 7 th days an upgrowth of the connective tissue of the wound occurred, creating a sulcus along the surface of the tooth. The epithelium 


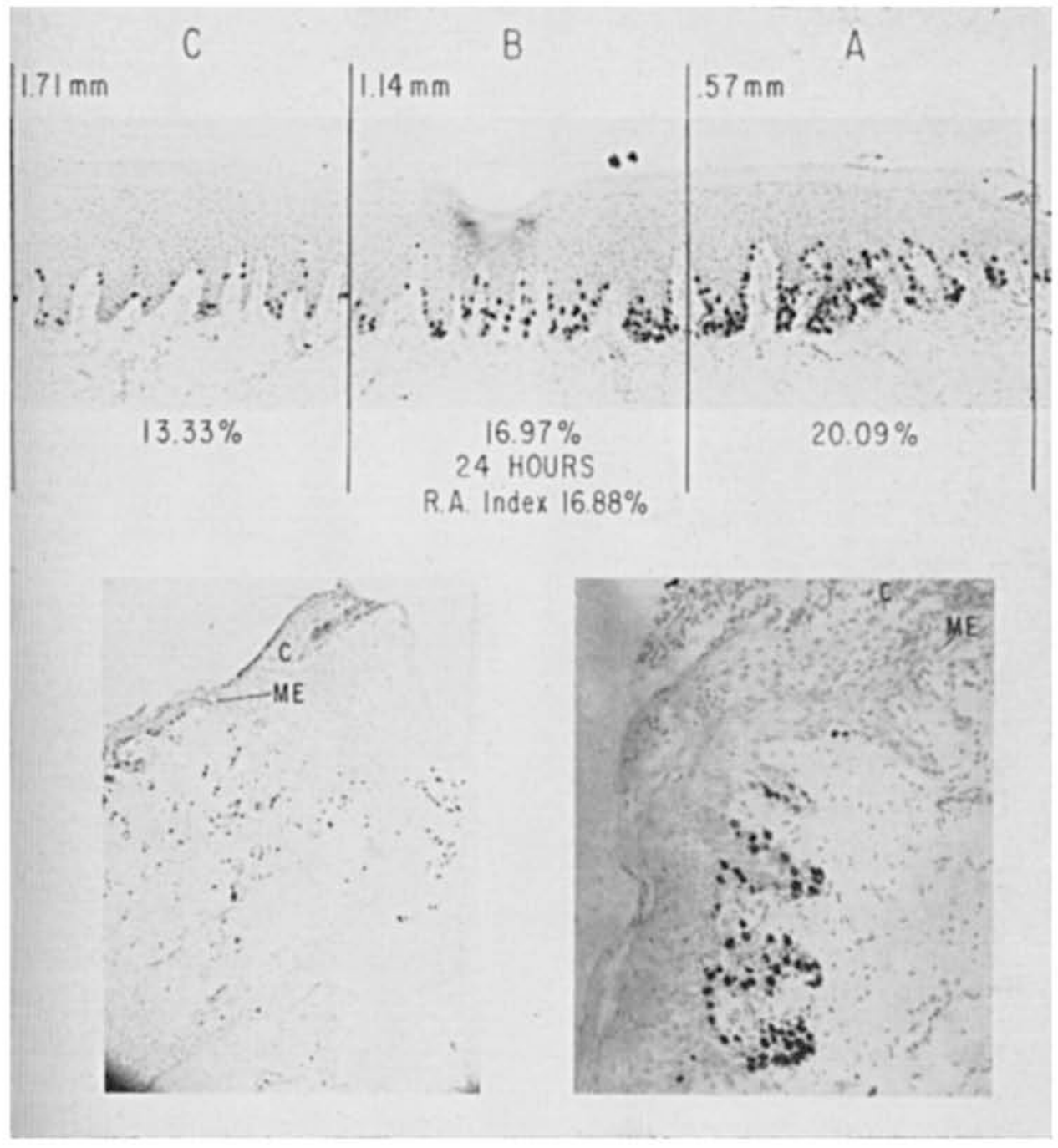

Fig. 4A. Radioautograph of wound margin, 24 hours. (Twenty-five hours after gingivectomy). Marked (A,B,C) as Fig. 2. Increased labeling in basal and deeper spinous layers of the attached gingival epithelium most pro-

nounced in zone A. (Magnification x105).
Fig. 4B. Low magnification of wound area 25 hours following gingivectomy and demonstrating the path of migrating epithelium. Migrating epithelium (ME), Clot (C). (Magnification x55).

Fig. 4C. Higher magnification of migrating epithelial wedge. Radioautograph 24 hours. (Twenty-five hours after gingivectomy). Migrating epithelium (ME). Clot (C). (Magnification x180).

migrated apically as a thin layer between the tooth surfaces and the connective tissue to reform a gingival sulcus.

Epithelial thickness, keratinization, and rete peg formation differed widely from section to section from the 7th to the 14th day (Fig. $8 \mathrm{~A}, \mathrm{~B}, \mathrm{C}$ ). It appeared, however, that keratinization was definitely established on the surface of the newly formed marginal gingiva by the 14th day. Radioactivity indices declined at the wound margin to $2.51 \%, 3.54 \%$, and $2.29 \%$ at 7,9 , and 14 days postgingivectomy, indicating that the demand for cells for regeneration from the original wound margin was ended. In areas where epithelialization was not complete, such as in the newly formed sulcus and in interproximal areas, the migrating epithelium exhibited numerous labeled cells con- 


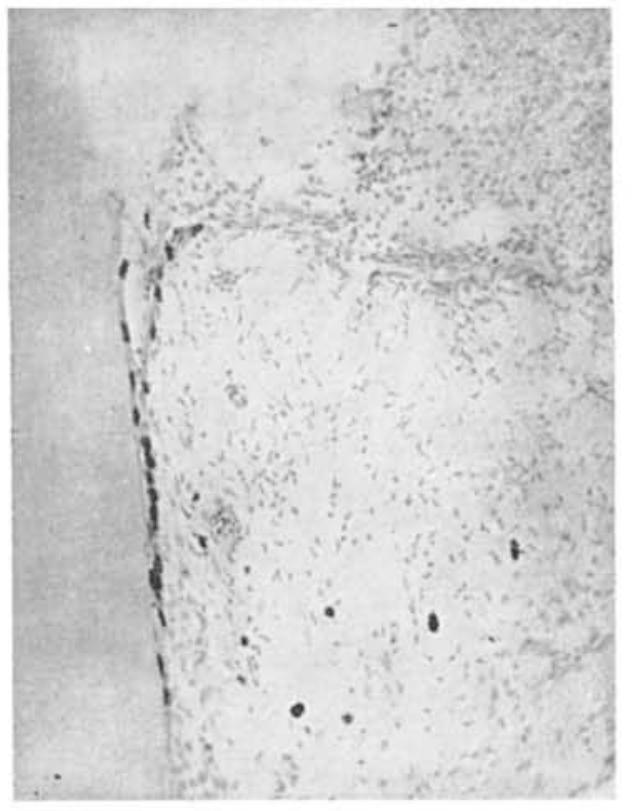

Fig. 5. Residual epithelial attachment adhering to tooth. Radioautograph 24 hours. (Twenty-five hours after gingivectomy). Migration from the epithelial attachment to beneath the polymorphonuclear infiltrated connective tissue and clot at the level of the nification $\mathrm{x} 180$ ).

centrated along the basal layer immediately at the migrating tip. The radioactivity indices of these areas at 9 days following wounding averaged $18.51 \%$. Therefore, after five days following gingivectomy new cells for migration were being produced at the border of the migrating epithelial wedge and not at the original wound margin.

Twenty-one days following gingivectomy the outer surface of the marginal gingiva was normal in appearance (Fig. 9). However, the surface of the gingival sulcus was not completely epithelialized in many sections. Unepithelialized areas as well as elongated epithelial pegs containing many labeled cells were present near the base of the sulcus, and inflammation was still present in the adjacent connective tissues. The radioactivity index of the attached gingiva was $2.51 \%$, similar to the 7,9 , and 14 day indices.

By 35 days following gingivectomy the epithelium of the gingival sulcus was well organized as a thin layer closely adapted

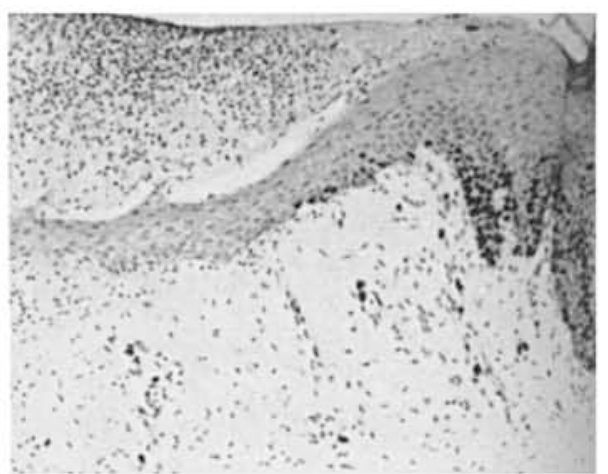

Fig. 6A. Gingival epithelium at wound margin. Radioautograph 48 hours. (Forty-nine hours after gingivectomy). Marked synthesis of DNA in cells at origi-
nal wound margin to the right. Note relation of minal wound margin to the right. Note relation of milying connective tissue toward left. Labeled cell in the regenerating epithelium (middle of picture). (Magnification x105).

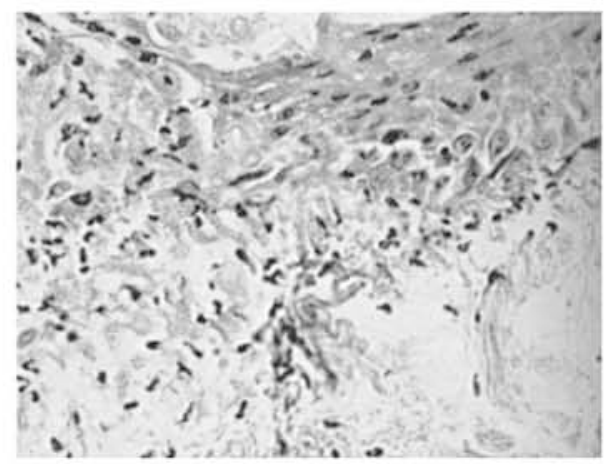

Fig. 6B. Junction of tip of migrating epithelial wedge and surrounding connective tissue 49 hours after gingivectomy. Note epithelial cells penetrating into necrotic connective tissue. (H and $\mathrm{E}$ stains). (Magnification $\mathrm{x} 1000$ ).

to the tooth surface (Fig. 10). Plasma cells and lymphocytes were present in the connective tissue adjacent to the gingival sulcus to the level of the epithelial attachment. With the exception of its more apical location, the epithelial attachment of the 35 day specimens was $1.53 \%$ which is similar to the control index of $1.32 \%$.

\section{DISCUSSION}

The general pattern of epithelialization observed during the present investigation was in accord with previous reports. The epithelium migrated and regenerated from the wound margin to the tooth, a distance of approximately $3 \mathrm{~mm}$ in 5 to 6 days at a 


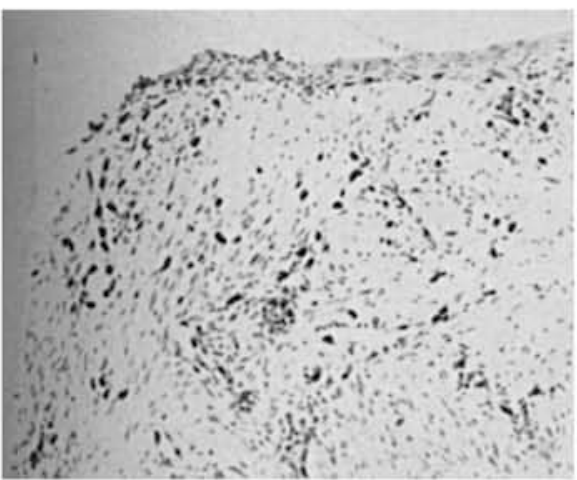

Fig. 7. Edge of regenerating gingival epithelium 5 days following gingivectomy demonstrating labeled cells in basal layer. Neck of
sion. (Magnification x135).

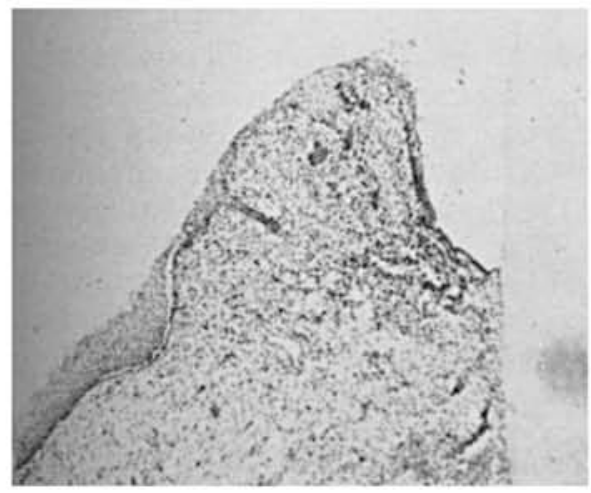

Fig. 8B. Nine days following gingivectomy the healing less advanced than in $8 \mathrm{~A}$. Severe inflammation. (Magnification x55).

rate of approximately $0.5 \mathrm{~mm}$ per day. An upgrowth of the connective tissue of the wound then occurred, creating a sulcus along the tooth surface which subsequently became epithelialized and established a new epithelial attachment. By 35 days the marginal gingiva was completely regenerated and indistinguishable from that of control sections.

However, several findings differed from previous reports of similar studies of gingival healing.

Gelfant ${ }^{18}$ in a study of healing of the rat ear, described the presence of a unique population of cells held in G-2 phase of premitosis for a long period of time, apparently able to rapidly undergo mitosis

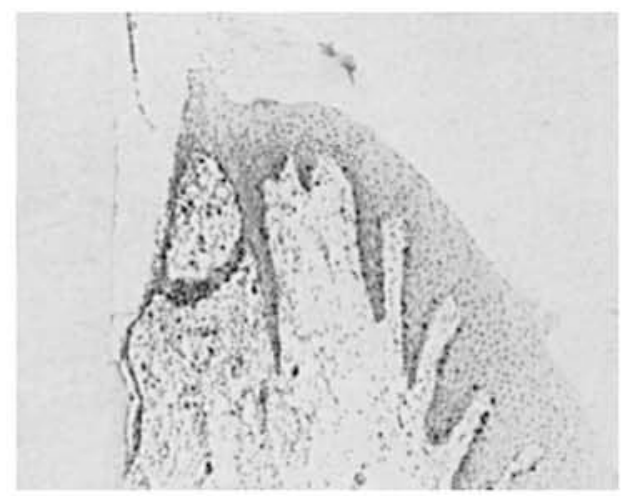
Fig. 8A. Seven days following gingivectomy, there level demonstrated in Fig. 7 and complete epithelialization of surface. Healing of gingival sulcus incomplete. Residual inflammation. (Magnification x87).

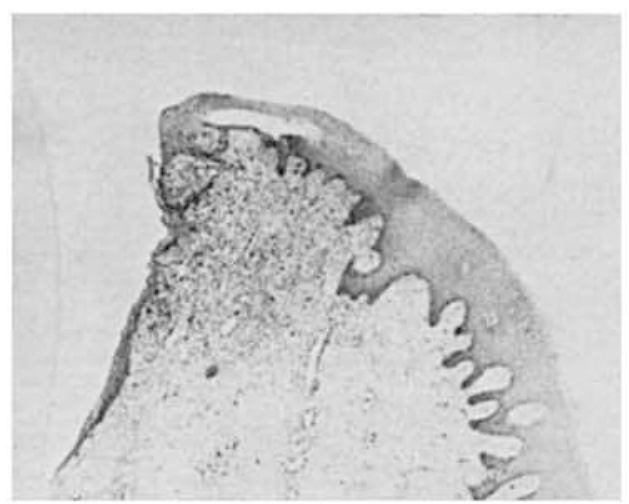

Fig. 8C. Fourteen days following gingivectomy a well-defined keratin layer covers the surface of the marginal gingiva. Inflammation and
ing in sulcus. (Magnification x55).

when a need, such as injury, arises. Observations of radioautographs and hematoxylin and eosin stained slides at early hours following injury in the present study failed to reveal such a cell population rapidly undergoing mitosis. This does not preclude the existence of such a population, however, in that our first radioautographic observation periods were 2 and 5 hours following gingivectomy and rapid mitotic activity could possibly have occurred unobserved.

Migration of epithelial cells from the wound margin of monkey gingiva was an early phenomenon occurring well in advance of the increased synthesis of DNA by epithelial cells at the wound margin. 


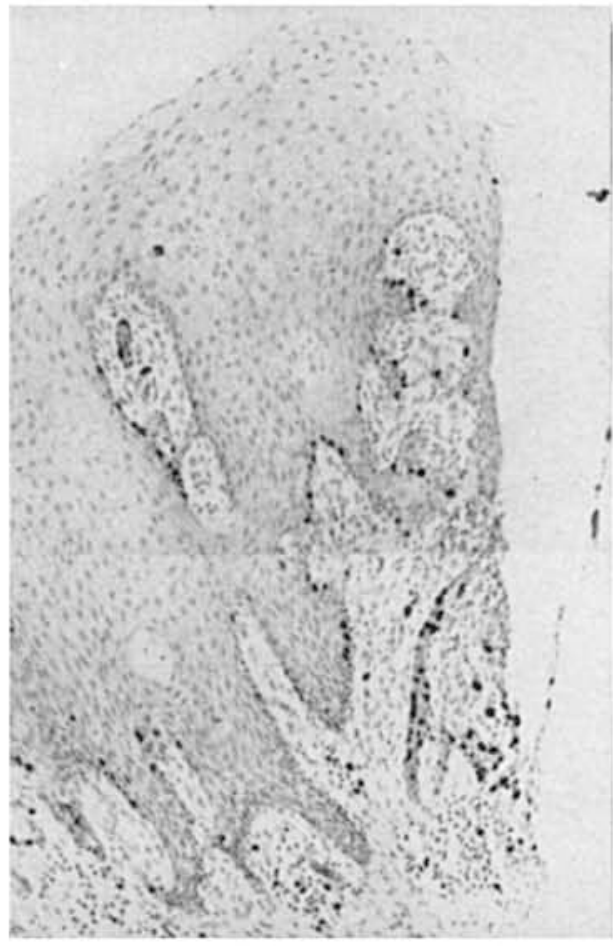

Fig. 9. Marginal gingiva and sulcular epithelium 21 days following gingivectomy. The top portion of the photomicrograph depicts the coronal part of the sulcular epithelium and marginal gingiva. Labeling in basal the apical portion of the sulcus not completely epithelialized. Inflammation and numerous labeled cells in epithelial pegs. (Magnification $\mathrm{x} 105$ ).

The high rate of synthesis of DNA in approximately $2 \mathrm{~mm}$ of epithelium at the wound margin at 24 hours following injury agrees with the increased mitosis during the 2 nd day which has been observed in other studies. ${ }^{16,19}$

McHugh and Persson, ${ }^{20}$ using fluorescence microscopy, observed in the healing gingiva of dogs, the presence of a peg or "factory" or epithelium which extended into the connective tissue at the wound margin and provided cells for migration and wound closure. This peg was present from the 2 nd or 4 th day to the 9 th or 10 th day following wounding. The authors state: "In examining the epithelial cells overlying the granulation tissue in early stages it is seen that the epithelial cells on the surface are younger than those underneath. From this it seems reasonable to assume that divi-

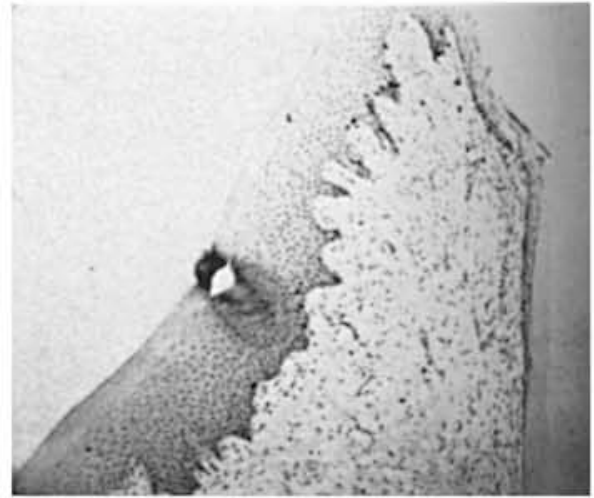

Fig. 10. Marginal gingiva 35 days following gingicemental surface. Some lymphocytes and plasma cells are present under the sulcus epithelium. (Magnification $\times 87$ ).

sion of the epithelial cells covering the lesion does not occur in the early stages and that the cells originate from the 'peg' formation and slide out over the surface of the cells already there."

"The production of epithelial cells by the 'peg' appears to be the main source of cells for the healing lesion up to about the 9th or 10th day after production of the lesion." 20

The presence of such a "peg" at the wound margin, producing cells in sufficient quantity to satisfy migration, would be obvious in a tritiated thymidine study in that a "peg" containing many cells synthesizing DNA in preparation for mitosis should be easily demonstrated. However, in the present investigation such a "peg" did not exist.

It appears that cells for initial migration from the wound margin were provided for by increased mitosis in the epithelium within $2 \mathrm{~mm}$ of the wound edge. However, after 2 to 3 days, as stratification of the migrating epithelium at the original wound margin occurred, cells necessary for migration were produced by the basal cells of the migrating epithelial wedge as well as at the wound margin. The decrease in radioactivity indices at the wound margin from 24 hours to 9 days tends to substantiate this concept.

Although the epithelial migration and regeneration starts at the margin of the 


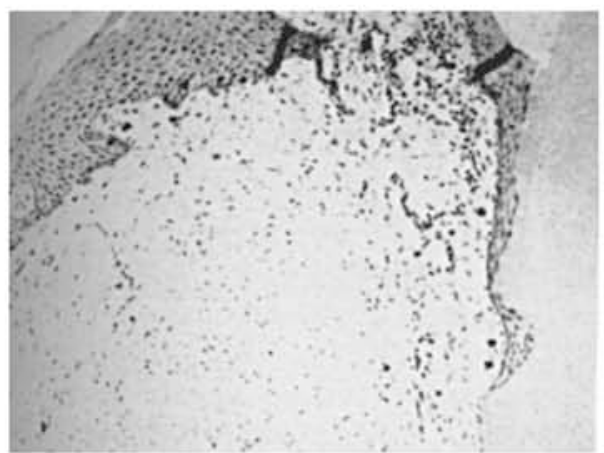

Fig. 11. Epithelial attachment 35 days following ginnivectomy demonstrating epithelial ingrowth into knife nicks on tooth created during incision. Minimal labeling in the new epithelial attachment. Slight inflammathe gingival sulcus at the cemento-enamel junction (toward top of picture). (Magnification $\times 87$ ).

wound, and could possibly have been stimulated as a result of the injury to the excised epithelium, the completion of healing occurred with mitosis in the new epithelium far from the wound margin and after the epithelium at the original wound margin had settled down to the control level of DNA synthesis, thus indicating that the stimulus for epithelial regeneration must come either from within the epithelium or from the exposed or incompletely covered connective tissues.

The completion of the epithelial healing of the gingivectomy wound is dependent on establishment of a new epithelial seal or attachment to the tooth at the bottom of the gingival sulcus. Epithelialization is delayed and disturbed in the presence of inflammation and if bacterial plaques already have gained foothold on the tooth surface during the formation of the new gingival crevice there may never be complete healing with an adequate epithelial seal or attachment. Completion of healing also is dependent on establishment of collagenous fibers in the free gingiva adapting the free gingiva closely to the tooth, thus establishing and maintaining a physiologic gingival crevice with an intact epithelial attachment. It is therefore essential for complete healing of a gingivectomy wound that the tooth surface and the crevicular area are kept as clean as possible during the healing period which in this instance was complete in 35 days but was incomplete in 21 days.

It is of great clinical significance that the surface of the gingiva healed to normal appearance several weeks before the crevicular healing was completed. Thus from the standpoint of periodontal health, the most crucial period of healing is after the gingival surface has healed and even keratinized. If the results of this study can be applied to humans, these results should serve to emphasize the need for very rigidly supervised periodontal care the first few weeks after removal of the post-surgical dressing in gingivectomy patients since inflammation is apt to occur during this critical period.

Several of the teeth had nicks or notches as a result of the gingivectomy, as previously reported by Ramfjord and Costich ${ }^{8}$ in humans. Although one such area had been covered by a normal epithelial attachment in the 35 days specimen (Fig. 11), it appears that such surface irregularities may be hazards for bacterial and calculus retention if the epithelial seal in this area should be lost at a future date or if the nick is in an area not included in the epithelial seal. A normal epithelial seal or attachment is characterized by very minimal mitotic activity and no underlying inflammation. However, slight inflammation and some mitotic activity is always present at the junction between the crevicular epithelium and the epithelial attachment.

\section{SUMMARY}

Sequential healing of simple gingivectomy wounds was studied in three monkeys with histologic and radioautographic techniques. The initial response was necrosis at the wound margin and acute inflammation. Migration and increased synthesis of DNA in epithelial cells started between 12 and 24 hours after the surgery, and reached a peak activity at the border of the wound between 24 and 36 hours after the excision. The migrating epithelial cells wedged themselves between the "poly-band" 21 and the healing 
connective tissue, and reached the tooth in 5 to 7 days.

The outer surface of the gingiva was completely healed and keratinized in 2 weeks but it took between 3 and 5 weeks to complete the healing in the new gingival sulcus. There was minimal mitotic activity in the new epithelial attachment after the healing was complete.

\section{CONCLUSIONS}

The following conclusions can be made regarding healing of gingivectomy wounds in adult rhesus monkeys:

1. Migrating epithelial cells start to cover the wound between 12 and 24 hours following surgical excision.

2. The premitotic increased uptake of $\mathrm{H}^{3}$ thymidine initially is limited to a zone of $2 \mathrm{~mm}$ from the wound margin.

3. The highest degree of epithelial cell division takes place during the second day after the excision.

4. Premitotic activity in the migrating epithelial cells starts within 2 days after the surgery.

5. Complete healing of the sulcus aspect of the gingivectomy wound takes 4-5 weeks although the surface appears to be healed after 2 weeks.

6. The critical period for the complete healing of a gingivectomy wound is from 2 to 5 weeks after the surgery. Meticulous oral hygiene during this period is essential for establishment of a physiologic gingival sulcus.

7. There is very little mitotic activity in a normal epithelial attachment and the corresponding lack of inflammation indicates that this area is sealed off from bacteria and bacterial toxins.

\section{ACKNOWLEDGEMENT}

We would like to express our acknowledgement to Mrs. Joan E. Christian who prepared the slides and radioautographs and to $\mathrm{Mr}$. Charles $\mathrm{T}$ Knorpp, M.S., Assistant Chief, Radioisotope Unit, for his technical assistance. Both from the V.A. Hospital, Ann Arbor, Michigan.

\section{REFERENCES}

1. Stones, H. H.: Pyorrhea alveolaris: An analysis of some methods of treatment. Brit. Dent. J., 53:499. $508,1932$.

2. Waerhaug, J.: Depths of incision in gingivectomy. Oral Med., Oral Surg., and Oral Path., 8:707-718, 1955.

3. Persson, P.-A.: The healing process in the matginal periodontium after gingivectomy with special regard to the regeneration of epithelium. Odont. Task., 67:593-615, 1959.

4. Klingsberg, J and Butcher, E, O.: Epithelial function in periodontal repair in the rat. $J$. Periodont. $34: 315-321,1963$.

5. Lundquist, G. R.: Regeneration of the gingivae following surgical treatment of pyorrhea with special reference to the epithelium. J. Amer. Dent. Assn., 16: 128-129, 1929.

6. Bernier, J. L. and Kaplan, H.: Repair of gingival tissue after surgical intervention. J. Amer. Dent. Assn., $35: 697-705,1947$.

7. Glickman, I.: The effect of prescaling upon healing following periodontal surgery: A clinical and histologic study. J. Dent. Med., 16:19-22, 1961.

8. Ramfjord, S. P. and Costich, E. R.: Healing afte simple gingivectomy. J. Periodont., 34:401-415, 1963.

9. Brachet, J.: Biochemical cytology. N.Y. Academic Press 1957, 597 p. (p. 179).

10. Cronkite, E. P., et al.: The use of tritiated thymidine in the study of DNA synthesis and cell turnover in hemopoietic tissues. Lab. Invest. 8:263-277, 1959.

11. Hurme, V. O. and Waganen, G.: Basic data on the emergence of permanent teeth in the Rhesus monkey. Am. Philo. Soc. Proc., 105:105-140, 1961.

12. Bullough, M. W., in Wound Healing (Ed.) D. Slone. N.Y., London, Pergamon Press, 1961.

13. Bullough, W. S. and Lawrence, E. B.: A technique for the study of small epidermal wounds. Brit. J. Exper. Path., 38:273-283, 1957.

14. Engler, W. O., Ramfjord, S. P. and Hiniker, J. I.: Development of epithelial attachment and gingival sulcus in Rhesus monkeys. J. Periodont., 36:44-56, 1965

15. Block, P., Serter, I. and Oehlert, W.: Autoradiographic studies of the initial cellular response to injury. Exp. Cell Res., 30:311-321, 1963.

16. Firket, $H$. in Wound Healing and Tissue Repair. W. B. Patterson (Ed.) Univ. of Chicago Press, 1956. $X I+83$ p. (p. 14).

17. Messier, B. and Leblond, C. P.: Cell proliferation and migration as revealed by radioautography after injection of thymidine $\mathrm{H}^{3}$ into male rats and mice. Am. J. Anat., 106:247, 1960.

18. Gelfant, S.: Initiation of mitosis in relation to the cell division cycle. Exp. Cell Res., 26:395-403, 1962.

19. Orban, B. and Archer, E. A.: Dynamics of wound healing following elimination of gingival pockets. Am. J, Ortho. and Oral Surg., 31:40-54, 1945.

20. McHugh, W. D. and Persson, P.-A.: Finorescence microscopy of healing gingival epithelium. Acta Odont. Scand., 16:205-229, 1958.

21. Viziam, C. B., Matoltsy, A. G. and Mescon, H. Epithelialization of small wounds. J. Invest. Dermat. 43:499-507, 1964 . 